\title{
Bloqueo ecoguiado de fascia iliaca en el manejo perioperatorio en cirugía de cadera
}

\author{
Crippa NA. ${ }^{1,2}$, Cáceres J. ${ }^{1}$, Alonso R. ${ }^{1}$ \\ 1 Hospital San Roque, La Plata, Argentina. \\ 2 La Plata.
}

Introducción: El bloqueo de fascia iliaca (BFI) consiste en la inyección de anestésico local en dicho compartimento interfascial, tiene como fin anestesiar los nervios femoral y femorocutáneo que residen en su interior.

Objetivo y Métodos: Se comparo retrospectivamente la percepción del dolor en pacientes a los que les fue realizada esta técnica anestésica en el preoperatorio de cirugía de cadera, en relación a pacientes que no. Para eso, Se revisaron las historias clínicas del Servicio de Anestesia.

Se consideraron dos grupos: aquellos que habían recibido el bloqueo de fascia iliaca (BFI) guiado por ecografía, y aquellos que no lo recibieron.

Criterios de inclusión: adultos, en plan de cirugía de cadera, sin signos de infección en el sitio de trabajo, en condiciones neurológicas aptas para comprender preguntas y comunicarse correctamente. Primero se realizó el bloqueo ecoguíado de fascia iliaca (bupivacaína $0,5 \% 20 \mathrm{ml}$ ) y luego el bloqueo subaracnoideo. Aquellos que no recibieron el BFI, solamente recibieron el bloqueo subaracnoideo, según historia clínica. El resultado de BFI se evaluó a los 15 minutos, al momento de sentar al paciente para el bloqueo subaracnoideo, y a las 12 horas de realizado el BFI. Se utilizó la escala numérica verbal para evaluar el dolor (ENV)ํ.

Resultados: Se incluyeron 10 pacientes con BFI y 8 pacientes sin BFI, todos de sexo femenino, siendo el rango etáreo entre 34 y 93 años.

Se comparó el dolor presentado a los 15 minutos de realizado el BFI, en posición sentada pre bloqueo subaracnoideo y a las 12 horas (postquirúrgico). Se encontró que aquellos que recibieron el BFI presentaron significativamente menos dolor que aquellos que no lo recibieron a los 15 minutos (precirugía) ( $\mathrm{p}=0,0001$ : IC99\% 8,63-11,36), en posición sentada antes de realizar el bloqueo subaracnoideo $(\mathrm{p}=0,0001$ : IC99\% 8,63-11,36) y a las 12 horas del bloqueo (postcirugía) ( $\mathrm{p}=0,0128$ : IC99\% 3,63-6,36) (Tabla1).

Conclusión: El bloqueo de fascia iliaca resulta útil para el manejo de dolor preoperatorio de cadera, disminuyendo el dolor causado por la patología de base y por la posición sentada al recibir anestesia subaracnoidea. Esto se traduce en confort para el paciente y para el trabajo del anestesiólogo.

Referencias: 1. Downie WW, Leatham PA, Rhind VM, Wright V, Branco JA, Anderson JA. Studies with pain rating scales. Ann Rheum Dis. 1978 Aug;37(4):378-81.

https://doi.org/10.25237/congresoclasa2019.47 